\title{
El Real Madrid y el origen del fútbol como espectáculo de masas, 1923-1936
}

\author{
José María BÁEZ y PÉREZ DE TudelA \\ Doctor en Humanidades, Geografía, Historia y Arte \\ pepebaez@colegiofem.es
}

Recibido: 16 de julio de 2012.

Aceptado: 20 de agosto de 2012.

\begin{abstract}
Resumen
El origen de la pasión por el fútbol se halla en los años veinte y treinta del siglo pasado, período en el que se produjo la profesionalización del deporte. El Real Madrid, con sus éxitos en la Copa de España y la Liga, fue uno de los equipos que contribuyó a la consolidación del deporte como espectáculo de masas. Los medios de comunicación como la prensa, la radio y el cine dieron testimonio de esta difusión del fútbol. La expansión del espectáculo deportivo se produjo al mismo tiempo que la población reivindicaba una mayor participación en los asuntos públicos. El ocio de masas convivió con la movilización política, no fue un instrumento para someter a la población.
\end{abstract}

Palabras clave: Fútbol; espectáculos; prensa; radio; cine; política.

\section{Real Madrid and the origin of football as mass' spectacle, 1923-1936}

\begin{abstract}
The origin of football's passion became in the 1920's and 1930's, period in which sport made professional. Real Madrid, with its victories in Spanish' Cup and League, was one of the teams that contributed to the consolidation of sports as spectacle. Mass media, as press, radio and cinema, showed this diffusion of football. The increase of the sportive spectacle was as the same time that people claimed for a bigger participation in the public affairs. Mass leisure lived together with politic mobilization, it wasn't an instrument to dominate people.
\end{abstract}

Key words: Football; spectacles; press; radio; cinema; politics.

\section{Referencia normalizada}

Báez y Pérez de Tudela, J. M. (2012). El Real Madrid y el origen del fútbol como espectáculo de masas, 1923-1936. Historia y Comunicación Social, Vol. 17, páginas 159-180.

Sumario: 1. Introducción. 2. Estado de la cuestión y objetivo de la investigación. 3. Metodología. 4. El origen del fútbol como espectáculo de masas. 5. Los medios de comunicación de masas informan sobre el fútbol. 6. Conclusiones. 7. Bibliografía.

\section{Introducción}

El fútbol se ha convertido en el deporte que mejor ejemplifica la globalización del mundo actual. Personas de todas las edades, de cualquier condición social, sin importar diferencias de religión o sexo, disfrutan con el espectáculo que ofrecen dos equipos de once jugadores disputándose un balón. Su capacidad para interesar a la población se traduce en la necesidad de recoger una exhaustiva información sobre 
todo cuanto rodea a esta práctica deportiva. La prensa escrita, los canales de televisión, la radio o internet ofrecen profusos y actualizados reportajes sobre los principales equipos, las selecciones nacionales y sus grandes estrellas. El mayor volumen de noticias se genera con las grandes competiciones, la Liga y la Copa, que alimentan el interés de los aficionados durante los nueve meses que duran y sirven de base para las confrontaciones internacionales como la Champions League. Las competiciones de las selecciones nacionales como el Mundial o la Eurocopa actúan como elemento de cohesión social de los países.

El frenético ritmo de este modelo puede hacer pensar que es un espectáculo surgido en los últimos tiempos o, como mucho, durante la segunda mitad del siglo XX. Sin embargo, las bases de esta pasión se encuentran mucho tiempo antes. En los años posteriores a la Primera Guerra Mundial, en las décadas de los veinte y los treinta, nació el modelo del balompié como diversión preferida por amplios sectores de la ciudadanía. La iniciativa correspondió a las grandes ciudades europeas, que establecieron un modelo de ocio en consonancia con los cambios sociales y económicos introducidos por la Segunda Revolución Industrial. El tiempo de trabajo y el tiempo libre se delimitaron claramente, el descanso dominical era una conquista de los trabajadores ya consolidada y el aumento del nivel de vida permitió destinar una parte de la renta a la diversión. Estas premisas se ajustaron a las virtudes que ofrece el fútbol como diversión: se trata de un deporte con unas reglas fáciles de comprender, se disputa en estadios que congregan a miles de personas y la incertidumbre del resultado añade la emoción que le hace tan atractivo. Los habitantes de la ciudad se identifican con el principal equipo, el que más títulos consigue.

Hace noventa años se plantó en España la semilla que convirtió a los deportes en un pilar básico del ocio y al fútbol en su principal representante. En ese tiempo se consolidó como una diversión que competía con otras manifestaciones de la industria cultural, como el cine, el teatro, los toros o la zarzuela. La expansión que desde entonces ha tenido la información sobre el deporte y la internacionalización que ha vivido son la consecuencia lógica de la gran aceptación que tuvo por parte de la sociedad. El estudio de un caso concreto, el que vivió la ciudad de Madrid desde principios de los años veinte, ilustra sobre la forma en la que el fútbol se ha convertido en un espectáculo de masas y cómo un club, el Real Madrid, logró que los habitantes de la capital de España se identificasen con sus éxitos.

\section{Estado de la cuestión y objetivo de la investigación}

La importancia creciente que tiene el mundo del ocio en la vida cotidiana ha provocado un reciente interés en la comunidad científica por estudiar cuáles han sido los orígenes de esta situación. Se trata de un campo todavía poco explorado que poco a poco cuenta con estudios concretos que permiten conocer mejor la evolución de los acontecimientos. En este contexto, los estudios sobre el desarrollo de la industria cultural forman un corpus cada vez más consolidado en el campo de la Historia. El objetivo concreto de esta investigación se centra en mostrar la importancia que tiene 
el ocio como elemento vertebrador de la sociedad y su estrecha relación con los acontecimientos políticos. El acceso de buena parte de la población al tiempo libre es una conquista social que permite compaginar a los ciudadanos la asistencia a mítines políticos y la identificación con un equipo de fútbol.

\section{Metodología}

La metodología empleada para la realización de este estudio ha consistido en un estudio directo de las fuentes primarias de la época. Se ha dado especial importancia a la prensa escrita, ya que recoge de manera directa la percepción que sobre el deporte tenía la gente de la calle. En principio la prensa más utilizada ha sido la generalista, pues remite a la visión que el ciudadano de a pie tenía del deporte. La lectura de la prensa deportiva especializada ha servido para matizar y completar información específica. Junto al estudio en la Hemeroteca ha sido básica la consulta de libros de memorias en los que los protagonistas recogen sus recuerdos sobre la época. Por último, la realización de un estudio que abarca múltiples disciplinas, entre ellas la Historia, la Sociología, la Geografía Urbana, la Arquitectura, el Periodismo y la Antropología ha requerido recurrir a obras de todas estas ciencias para dotar al estudio de la pertinente base teórica en cada tema.

\section{El origen del fútbol como espectáculo de masas}

El 13 de mayo de 1923 se inauguró en Madrid el Stadium Metropolitano, un campo de fútbol con capacidad para 23.000 espectadores. Se convirtió en el recinto de ocio con mayor capacidad de la ciudad, que hasta ese momento era la plaza de toros de la calle O'Donnell, cuyo aforo alcanzaba los 13.000 asientos. La apertura del Stadium mostraba el interés que el deporte generaba entre la población de Madrid, que casi alcanzaba el millón de habitantes. Veinte años antes, el fútbol era una actividad casi desconocida para los madrileños, por lo que se podía definir su expansión como meteórica. La aceptación del deporte por la sociedad industrial estriba en que se convierte en elemento vertebrador de la población y regula las tensiones individuales y colectivas que genera la sociedad industrial (Elías, 1992: 56).

A principios del siglo pasado el deporte, incluido el fútbol, lo practicaban personas de clase media o alta, que dedicaban parte de su tiempo libre a este nuevo entretenimiento procedente de Gran Bretaña. El primer equipo que se creó en Madrid fue el Foot-Ball Sky, cuyo nombre delataba la influencia inglesa en los términos deportivos, que todavía hoy resulta patente. Estaba integrado por estudiantes pertenecientes a la Institución Libre de Enseñanza, cuyos profesores habían asistido a clases en Oxford y Cambridge. El fútbol ganó adeptos entre los jóvenes y, con motivo de las fiestas organizadas en 1902 para celebrar la subida al trono de Alfonso XIII, se preparó un torneo entre diversos equipos de España. Uno de los impulsores 
de esta iniciativa fue el Madrid Foot-Ball Club, el futuro Real Madrid. El éxito de la competición, ganada por el Vizcaya en la final que disputó al Barcelona, significó el origen del torneo decano del fútbol español, la Copa del Rey, que durante muchos años se denominó Campeonato de España.

En los años siguientes, el Madrid Foot-Ball Club logró numerosos triunfos en el torneo. Logró alzarse con la victoria cuatro años seguidos de 1905 a 1908, siendo el primer equipo que logró la Copa en propiedad, ya que ésta se entregaba al vencer en tres ediciones consecutivas. Estas victorias ayudaron a la popularización de un deporte que se disputaba en campos de tierra, a los que acudían los espectadores a pasar el rato, sin necesidad de pagar una entrada. La difusión que alcanzó el deporte propició la creación en Madrid de la Federación Española de Clubes de Foot-Ball. Se produjo el 14 de octubre de 1909, en la taberna La Taurina, con representantes de Vigo, Coruña, Avilés, Cartagena, Huelva, Bilbao y Madrid (Varios Autores, 2002: I, 77).

La nueva diversión gozaba del agrado del público, lo que llevó a los dirigentes de los equipos a plantearse cobrar por asistir a los encuentros. Eso significaba un cambio radical en la relación que mantenían con los aficionados. El fútbol se integraba en la industria cultural, definida por la compra de una entrada para acceder al espectáculo. El primer equipo madrileño que cerró su campo fue el Madrid Football Club. En 1912 gastó 6.000 pesetas en allanar y vallar su campo, situado en la calle O'Donnell, muy próximo a la plaza de toros. El dinero lo consiguió con cuestaciones entre los socios y la aportación de algunos directivos, como Pedro Parages, Carlos Padrós y Federico Revuelto (Sainz de Robles, 1952: 383 y ss. ). El fútbol iniciaba el camino hacia la conversión en negocio, regido por la ley de la oferta y la demanda.

El público respondió positivamente y siguió acudiendo a los partidos previo pago de una entrada. Pronto hicieron lo mismo otros equipos de la ciudad, entre los que destacaban el Athlétic de Madrid y el Rácing Club, los que se disputaban con el Madrid F.C. la primacía en el fútbol de la capital a través del Campeonato Regional. El vencedor de esta competición se clasificaba para jugar el Campeonato de España, el único de alcance nacional que existía en el fútbol español. Una prueba del creciente éxito del fútbol entre los madrileños se vivió con motivo de un nuevo triunfo del Madrid Football Club en la Copa, en 1917. Tras nueve años sin títulos venció en la final, celebrada en Vigo, al Arenas de Guecho. En su regreso a la capital, cientos de aficionados celebraron eufóricos el triunfo de su equipo.

E1 29 de junio de 1920 Alfonso XIII concedió el título de Real al Madrid Football Club, lo que inició una estrecha relación entre ambos. Ese mismo año, el combinado nacional participó en los Juegos Olímpicos de Amberes. En la selección debutó un joven portero de diecinueve años, Ricardo Zamora. Su memorable actuación en el partido contra Dinamarca, que ganó España por 1 a 0, dio origen a la famosa frase "uno cero y Zamora de portero". Al terminar el partido sus compañeros le sacaron a hombros del estadio. La excelente actuación de la selección, que logró la medalla de plata, ayudó a la popularización del fútbol en la sociedad española. Ya estaban sentadas las bases para convertir el deporte en espectáculo de masas.

En 1923 la afición desbordaba las posibilidades de acoger espectadores que 
tenían los viejos estadios, como reflejaba la siguiente crónica referida al partido entre el Real Madrid y la Gimnástica, que superó la capacidad del viejo estadio de O'Donnell:

El público que acudió el pasado domingo invadió el campo del Club Campeón. Decimos invadió, porque, agotadas las localidades, escaló las tapias y arrolló a los de las puertas, que, auxiliados por los guardias, sable en mano, trataron inútilmente de contener la imponente avalancha de aficionados. Tal era la expectación que este partido despertó$^{1}$.

Con estas expectativas no resultó extraño que los empresarios vieran en el fútbol un negocio prometedor. El tiempo libre que dejaba el trabajo permitía dedicar el domingo a actividades de ocio. Así se explica la inauguración ya citada del Stadium Metropolitano el 13 de mayo de 1923. La nueva instalación era un ejemplo de las nuevas tendencias urbanísticas que dominaban en la ciudad, uniendo transportes, viviendas y espectáculos. Su origen hay que buscarlo unos años antes. El 17 de octubre de 1919, se había inaugurado la primera línea de metro con el trayecto SolCuatro Caminos. La empresa constructora era la Compañía Metropolitano Alfonso XIII. Como la entidad no conseguía amortizar la inversión con la venta de billetes, logró la concesión para construir viviendas en la Avenida de Reina Victoria, aledaña a Cuatro Caminos. Se constituyó la Compañía Urbanizadora Metropolitana que levantó el gran campo de deportes, con suelo de hierba, al final de dicha vía. Su vinculación con la sociedad constructora del suburbano es la que explica su denominación de Stadium Metropolitano. El nuevo coliseo serviría para aumentar los ingresos de una empresa que diversificaba cada vez más sus actividades y que ahora entraba en el sector del ocio de masas. El Real Madrid intentó que le cediesen el terreno en exclusiva pero los constructores preferían alquilar la instalación a otros equipos que disputaban el Campeonato Regional, que eran, además del club blanco, el Athlétic de Madrid, el Rácing, la Gimnástica y el Unión Sporting. El equipo merengue se negó a compartir la instalación, preocupado por perder la posición hegemónica que había logrado en el fútbol madrileño, quedando la flamante construcción para el uso del resto de las escuadras.

El Stadium se convirtió en la sede del resto de los equipos madrileños. Las entradas experimentaron un considerable aumento, pese a lo cual el público mantuvo su asistencia a los estadios. El éxito de la nueva instalación se comprueba en la crónica que narra el partido que disputaron en el nuevo campo el Athlétic de Madrid y el Real Madrid.

¿Habría 12.000 espectadores? Yo creo que había más. Lo cierto es que el día 17 de junio, y con precios altos, a que no está acostumbrada nuestra afición, se vio de manera bien clara que, dando partidos de emoción, como siempre que jueguen estos equipos, el público acude. Estos eternos y leales rivales, Athlétic y Madrid, son capaces e incapaces de todo lo bueno y lo malo que en el juego de fútbol puede realizarse ${ }^{2}$.

El Real Madrid, que no quería quedar a expensas de los deseos de los propieta- 
rios del Stadium, apostó por disponer de un patrimonio propio y construir su propio estadio. El coste de la operación ascendía a un millón de pesetas. Ante la dificultad para financiar la operación con préstamos de los bancos, los dirigentes del Real Madrid confiaron en la aportación de los aficionados. Confiaban alcanzar los 3.000 socios, que pagando una cuota de cinco pesetas al mes, alcanzarían las 180.000 pesetas al año. Por la venta de entradas esperaban recaudar 75.000 pesetas. El dinero se repartiría entre el Club y la empresa constructora. Los avales los consiguió el marqués de Bolarque gracias a la colaboración del Banco Urquijo, organización decisiva en el desarrollo del fútbol madrileño. Mientras se construía el nuevo estadio, abandonó el campo de tierra de O'Donnell y se trasladó al velódromo de Ciudad Lineal, en la calle Arturo Soria. El suelo era de césped pero el estadio se hallaba en una zona muy alejada del centro que resultaba de difícil acceso para los aficionados.

El golpe de Estado del general Miguel Primo de Rivera de septiembre de 1923 no modificó la competición futbolística, a la que el poder político prestaba todavía escasa atención. En 1924 Madrid abrió su segundo gran estadio, confirmando el poder de convocatoria del fútbol. El campo de Chamartín se inauguró el 17 de mayo de 1924. Su aforo de 15.000 espectadores era inferior al del Stadium, pero el club poseía una propiedad inmobiliaria que le aseguraba la independencia en su actividad y que resultó clave para el futuro de la entidad. El Stadium Metropolitano y el de Chamartín confirmaron las posibilidades que ofrecía el fútbol como negocio capaz de atraer a miles de espectadores a sus encuentros. El ocio se hizo más laico: el campo de fútbol se convirtió en el santuario de una nueva fe, la catedral de una nueva religión cuyos ídolos eran los jugadores. El ritual de la misa dominical se vio en parte sustituido por el de la asistencia al partido de fútbol.

Los años siguientes vivieron la profesionalización del fútbol, consecuencia lógica de la conversión del fútbol en un producto de la industria cultural. Los equipos necesitaban ofrecer a los clientes que acudían los domingos al estadio un espectáculo de calidad y para ello debían contar con profesionales que se dedicaran en exclusiva a esta actividad (Scher, 1988: 24). El deporte amateur era una idea nostálgica, según la cual la actividad física era un complemento a la tarea intelectual o laboral del individuo, no un medio para ganarse la vida. La vieja moral mesocrática condenaba que se recibiera dinero por jugar al fútbol, pero al mismo tiempo el público demanda futbolistas de calidad, con cualidades físicas y técnicas, que pudieran jugar los partidos sin las trabas que suponía cumplir un horario de trabajo. Los desplazamientos en la España de los años veinte requerían muchas horas de ida y de vuelta. Los futbolistas que disputaban el encuentro fuera de su ciudad pasaban tres días fuera de su hogar. Este ritmo era incompatible con un empleo normal. Por ello surgió, a finales de la década de 1910 lo que se llamó el "amateurismo marrón". Consistía en que los equipos concedían a sus deportistas beneficios tales como emplearles en empresas que aceptaban las ausencias del jugador, abonarles los desplazamientos y una pequeña dieta o, más directamente, pagarles por jugar, aunque el sueldo no lo declaraban.

El asunto del profesionalismo en el fútbol se había tratado con frecuencia en la FIFA (Federación Internacional de Fútbol Amateur), sin que se adoptara ninguna 
resolución definitiva. En 1925, la revista parisina Sporting aportó datos del profesionalismo encubierto en diversos países. En España, el F.C. Barcelona pagaba sueldos a sus jugadores, el más alto a José Samitier, que cobraba mil quinientas pesetas. Al año siguiente, el XXV Congreso de la FIFA, celebrado en Roma en mayo, acordó la separación entre amateurs y profesionales. El 30 de junio de 1926, la Federación Española aprobó el Reglamento que admitía la presencia de profesionales en sus competiciones y acabó con el amateurismo marrón. En Madrid, el Real Madrid, el Rácing y el Unión Sporting contrataron a algunos futbolistas profesionales mientras que la Gimnástica y el Athlétic mantuvieron a todos sus jugadores aficionados. El rechazo que podía generar esta situación entre los aficionados se apreciaba en el siguiente artículo:

Adiós al amateurismo marrón. Declararse profesional no es vergonzoso. La próxima campaña, pros y aficionados podrán jugar juntos (...) Conviene también esforzarse en desarraigar la equívoca idea de que la declaración de profesionalismo es algo infamante o vergonzoso, ya que la dignidad personal de amateurs y profesionales, ha de merecer igual estimación de todos 3 .

Las necesidades financieras que generaban los contratos de los jugadores profesionales obligaron a buscar nuevas fuentes de ingresos. El Real Madrid, que había iniciado sus giras europeas en un viaje en diciembre de 1920 por Italia, realizó su primera gira por América en el verano de 1927. De junio a septiembre viajó un equipo madridista reforzado con jugadores del Athlétic de Madrid, Athlétic de Bilbao, Osasuna y Tolosa. Como jefe de la expedición viajó el polifacético Santiago Bernabéu, antiguo jugador y entrenador, ahora encargado de funciones administrativas. El equipo regresó a Madrid el 28 de septiembre consiguiendo unos beneficios de 20.000 pesetas, lo que significó una buena inyección para las necesitadas arcas del club (BIRM, vol. I, $\mathrm{n}^{\circ} 25$, julio-1952: 4-7) .

A mediados de los años veinte ya existían grandes equipos, colosales estadios y una afición consolidada, pero sólo había una competición de dimensión nacional, la Copa del Rey. Al jugarse según el formato de eliminatorias, una temprana derrota dejaba al club sin ingresos relevantes durante el resto de la temporada. Por eso los grandes clubes querían crear un torneo en el que se aseguraran elevadas taquillas con partidos durante todo el curso. El modelo a imitar era la Liga inglesa, en la que los equipos de la máxima categoría jugaban todos contra todos en un sistema de enfrentamientos a doble vuelta.

El club vizcaíno Arenas de Guecho presentó en abril de 1927 una primera propuesta a la Federación Española. Al no ponerse de acuerdo los clubes interesados, la creación de la Liga se dilató un año. En el verano del año siguiente se llegó a un principio de acuerdo, pero hubo que esperar hasta el 22 de noviembre de 1928 para que la Real Federación Española de Fútbol aprobara la creación de la Liga. Contaba con dos divisiones, la primera con diez equipos y la segunda dividida en dos grupos de diez conjuntos cada uno. Los diez equipos que constituían lo que se llamó Primera Liga eran los seis equipos que habían ganado la Copa, es decir, el Athlétic de Bilbao, el Arenas de Guecho, el Real Unión de Irún, la Real Sociedad de San Sebastián, el 
F.C. Barcelona y el Real Madrid; los tres subcampeones, el Athlétic de Madrid y el Español y el Europa, ambos de Barcelona más un décimo equipo, el Rácing de Santander, que ganó el torneo disputado entre los equipos de segunda división. Los clubes se garantizaban en su estadio nueve partidos de competición oficial. La temporada 1928-1929 fue la primera en la que convivieron las dos competiciones nacionales pero no coincidieron en el tiempo, porque primero se disputó la Copa y, una vez terminada ésta, comenzó la Liga.

La final de la Copa, disputada entre el Real Madrid y el Español de Barcelona, se celebró en Valencia el domingo 3 de febrero de 1929 y se conoce con el nombre de "la final del agua". Miles de aficionados se habían desplazado para acompañar en el trascendental partido a sus equipos, por lo que el clima de excitación en la ciudad del Turia era superior al habitual. Los periódicos de ese mismo domingo anunciaban la detención de José Sánchez Guerra, político conservador y penúltimo presidente del gobierno antes del golpe de Estado de Primo de Rivera. La prensa no lo contaba, pero la razón del apresamiento fue que el veterano dirigente se dirigía con su hijo Rafael, futuro presidente del Real Madrid, al Regimiento Ligero de Artillería de Valencia para encabezar un golpe de Estado contra el dictador. La falta de libertades había provocado que el deporte sirviera para manifestar sentimientos nacionalistas, en especial en Cataluña. El miedo del gobierno a posibles desórdenes, unido a la presencia de miles de aficionados en la ciudad motivó que el gobernador civil de Valencia se reuniera con los capitanes de ambos equipos y les obligó a que jugaran el partido, fuera cual fuese el estado del terreno de juego. Se trató de una de las primeras intervenciones del poder político en el desarrollo de las competiciones futbolísticas, que hasta ese momento se habían mantenido al margen de los problemas deportivos. El campo de Mestalla se encontraba anegado de agua, lleno de barro e impracticable, pero el partido se jugó. Venció el Español por 2 goles a 1, con otra actuación estelar de su portero, el famoso Ricardo Zamora.

La primera edición de la Liga se disputó entre febrero y junio de 1929. La aparición del torneo influyó en el Campeonato Regional, pues carecía de sentido que los equipos que jugaban en primera división se enfrentaran en torneos menores. Los espectadores se cansaban de tantos Real Madrid-Athlétic. La crónica del partido de Liga disputado en el Metropolitano decía:

Pocos espectadores asistieron a este, en otras temporadas, interesante encuentro. Los antiguos rivales se encuentran hoy por sexta vez en la temporada, y al público, como a ellos, les parecen ya muchos partidos de máxima rivalidad ${ }^{5}$.

Los partidos de la selección española acaparaban la atención del público. El 15 de mayo de 1929 se disputó en el Stadium Metropolitano un encuentro contra Inglaterra, cuna del fútbol y símbolo por excelencia de este deporte. La expectación era tal que al partido asistieron 30.000 personas, superando con creces el aforo permitido. Tras un épico encuentro, el combinado nacional ganó por 4 goles a 3 y consiguió que una selección no británica ganara por primera vez al conjunto inglés. Los elogios a la selección, encabezada por Ricardo Zamora, fueron unánimes. 
La Liga captó el favor del público ya que durante muchos meses la afición disfrutaba de un entretenimiento que le permitía llenar sus horas de ocio tanto los domingos como los días laborables. Entre semana se discutía en los cafés y tertulias, donde se comentaban los partidos y se proponían las alineaciones más convenientes para cada encuentro. La temporada concluyó el 30 de junio con la victoria liguera del F.C. Barcelona y el subcampeonato para el Real Madrid.

El incremento de los partidos oficiales confirmaba el potencial del fútbol como espectáculo de masas. A partir de la temporada 1929-1930 se intercaló el calendario de las dos competiciones nacionales, la Copa y la Liga, para incrementar la emoción entre los seguidores y lograr un mayor beneficio económico con la subida del precio de las entradas. El éxito de la competición se aprecia en el siguiente artículo escrito por Pedro Escartín, árbitro y estudioso de las normas del fútbol:

La Liga interesa y cubre gastos siempre, cuando menos, cosa que antes no lográbamos con aquellos absurdos encuentros amistosos, con los que pretendíamos llenar los huecos dejados por los partidos oficiales (...) El público abarrota los campos, forma trenes especiales, y de vez en cuando, la hinchada salta al campo de juego y organiza algún pequeño carrousel, de los que antes no nos era dado ver hasta los campeonatos de España. No cabe duda que esto marcha 6

Los resultados de los equipos madrileños en esta Liga fueron decepcionantes. El Real Madrid se clasificó en quinto lugar y el Athlétic de Madrid sufrió las consecuencias de carecer de campo de juego propio. Los propietarios usaban el estadio como un centro de ocio polivalente, en el que celebraban espectáculos que les podían dar beneficios y, si era necesario, el fútbol cedía el paso a otros entretenimientos. La Federación prohibió, el 6 de octubre de 1929 que el Athlétic de Madrid "pueda jugar en el Stadium mientras se celebren en el mismo otros acontecimientos deportivos, como carreras de motocicletas" (Salazar, 2003: II, 9). Los partidos como local los disputó en Chamartín hasta la séptima jornada, el día 12 de enero de 1930, cuando volvió a jugar en el barrio de Cuatro Caminos (García, 1993: 23). Tantas idas y venidas al Stadium Metropolitano se reflejaron en la mala marcha de los rojiblancos y el Athlétic de Madrid bajó a segunda división.

El Real Madrid se clasificó por segundo año consecutivo para disputar la final de Copa. En esta ocasión el partido lo jugó contra el Athlétic de Bilbao en el campo de la Exposición Universal de Barcelona. El ambiente fue favorable a los bilbaínos, en un momento en el que los nacionalismos catalán y vasco se sentían víctimas de la represión gubernativa e identificaban al equipo madrileño con el centralismo del gobierno. El fútbol se convertía en vehículo de transmisión de las pasiones que en estos meses sacudían España, con la Monarquía tambaleándose tras la caída de la Dictadura. El partido concluyó con la victoria rojiblanca por 3 tantos a 2.

En 1930 se celebró el primer Campeonato del Mundo de Fútbol. La creación de este torneo fue fruto del deseo de los aficionados de contar con una competición oficial entre países, además de los Juegos Olímpicos y demostraba la pujanza del deporte a escala internacional, con Europa y América como máximos centros de difusión. Se disputó entre el 13 y el 30 de junio en Uruguay. El combinado español 
no acudió al evento, al que tampoco asistió buena parte de las selecciones europeas. Los países ausentes alegaron motivos económicos para justificar su decisión, pero se trató de un boicot, pues estaban disgustados con la sede elegida por la FIFA.

El verano de 1930 abrió el paso en España a los fichajes de jugadores a precios astronómicos. El club blanco se hizo con los servicios de Ricardo Zamora, el popular portero del Español de Barcelona y titular de la selección nacional, por la asombrosa cantidad de 150.000 pesetas. Sus despejes con los codos a los disparos de los rivales dieron nombre a un tipo de parada, la "zamorana". En esos momentos, El Divino Zamora era el único futbolista con una fama similar a la de los principales toreros. El objetivo de la contratación era, desde el punto de vista deportivo, lograr que el club recuperara la senda de los éxitos nacionales, que no había logrado desde el ya lejano año de 1917. Por la parte económica, la presencia del famoso portero atraería a numerosos aficionados al estadio de Chamartín, asegurando unas buenas taquillas. Desgraciadamente, en el segundo partido disputado por Zamora como merengue se lesionó de gravedad y apenas pudo intervenir en este curso. La Liga terminó el 5 de abril de 1931 con el Real Madrid clasificado en sexto lugar.

Las elecciones municipales celebradas el domingo siguiente, 12 de abril, dieron el triunfo en todas las grandes ciudades a la candidatura republicana, lo que provocó la caída de la Monarquía y la proclamación de la segunda República española el 14 de abril de 1931. El 21 de abril, La Gaceta publicó un decreto suprimiendo las denominaciones que reflejasen dependencia o subordinación de una entidad respecto del régimen monárquico (Moya, 1990: 78). El equipo merengue recuperó durante el período republicano su primitiva denominación de Madrid F.C. Los nuevos gobernantes aprovecharon la popularidad del fútbol como vehículo de conexión con el pueblo, como habían hecho los dirigentes monárquicos. En el España-Irlanda celebrado en Montjuich el 26 de abril, el presidente del gobierno provisional, Niceto Alcalá Zamora y el nacionalista Fransec Maciá "fueron aclamados por el público al atravesar el campo para saludar a los jugadores" (Gran Vida, n 334, 30-abril-1931: 116).

En el verano de 1931 el Madrid fichó a dos famosos defensas, Ciriaco y Quincoces, que consiguieron dar solidez al equipo y consolidar un conjunto campeón, capaz de enfrentarse a los otros dos grandes del fútbol español, el Barcelona y el Athlétic de Bilbao. Los partidos sumaban al atractivo de las figuras del balompié otras diversiones. En el encuentro liguero disputado en Chamartín contra el Barcelona, disputado el 31 de enero de 1932, realizó el saque de honor la guapa "Miss Madrid" ante un estadio lleno hasta la bandera. El Madrid consiguió ganar invicto esta Liga que concluyó el 3 de abril de 1932. La acertada política de fichajes logró el ansiado éxito y un gentío inmenso les recibió en el tren que trajo al equipo procedente de su último partido jugado en Barcelona.

La temporada 1932-1933 supuso el segundo título liguero para el Real Madrid, que acabó la competición como equipo menos goleado y con su delantero Manuel Olivares como máximo goleador. El equipo fue recibido en el Círculo de Bellas Artes por el alcalde Pedro Rico. El coliseo blanco vivió el 21 de mayo una de las victorias más abultadas de la historia de la selección española, que derrotó a Bulgaria por 13 
a 0. En la Copa el Madrid se clasificó para la final, que se celebró en Montjuich, de nuevo contra el Athlétic de Bilbao. Más de dos mil quinientos aficionados blancos se desplazaron hasta la ciudad condal con trenes especiales, autocares y vehículos privados. Pese al apoyo de sus seguidores, el equipo merengue perdió por 2 a 1 .

Los grandes resultados del equipo blanco provocaron que la afición al fútbol en Madrid aumentara sin cesar, generando la identificación entre el club y la ciudad. Por estas fechas, unos cien mil madrileños, uno de cada diez habitantes de la urbe, habían presenciado un partido en Chamartín (Bahamonde, 2002: 12). A ellos se sumaban los que habían acudido al Metropolitano y a los otros campos de la ciudad en los que había que pagar una entrada para ver un partido, lo que confirmaba el lugar preferente que ocupaba el fútbol dentro de la industria cultural. El respaldo del público le permitió al Madrid la consolidación del equipo y mantener su política de fichajes millonarios, siguiendo la dinámica empresarial del ocio de masas. Los equipos que carecieron de esta estructura empresarial no pudieron consolidarse.

El curso 1933-1934 supuso la consecución del título de la Copa de España, largamente anhelado. Este trofeo era el que gozaba de mayor prestigio entre los aficionados, que le daban más importancia que al recién creado torneo de la Liga. La final, disputada en Montjuich contra el Valencia el 6 de mayo de 1934, contó con la presencia de miles de aficionados madridistas. El estallido de alegría que vivió Madrid mostró el profundo arraigo del que gozaba el fútbol y la identificación de la urbe con su principal equipo. La ciudad se volcó en el recibimiento a sus héroes, que llegaron a la estación de Atocha y fueron escoltados hasta el local social del club, en la calle Recoletos, por unos diez mil forofos. El valor del título hizo que se presentara en la Casa de la Villa y que los jugadores hicieran entrega del trofeo al alcalde en el Ayuntamiento. Este año se adelantó el final del campeonato para que la selección acudiese al segundo Campeonato del Mundo de Fútbol, que se celebró en Italia. España eliminó a Brasil en octavos de final. En cuartos jugó contra la selección anfitriona. El partido acabó, después de dos prórrogas, con empate a uno, por lo que tuvo que jugarse un partido de desempate, en el que ganó Italia por 1 a 0 para desconsuelo de los aficionados españoles.

La temporada 1934-1935 introdujo dos novedades en la competición liguera. Se amplió el número de equipos de la Primera División a doce, con lo que el Athlétic de Madrid, subcampeón de segunda, recuperó su lugar en la máxima categoría. El segundo cambio fue la incorporación de jugadores extranjeros, con un cupo de dos futbolistas foráneos por equipo. Los conflictos políticos que vivió España en estos años se reflejaron en la actividad deportiva. La entrada de tres ministros de la CEDA (Confederación Española de Derechas Autónomas), partido al que la izquierda española identificaba con los nazis alemanes, provocó la revolución del 6 de octubre de 1934 en varias localidades españolas, entre ellas Madrid. El movimiento subversivo obligó a cancelar los partidos oficiales previstos en estas fechas, que se jugaron días después. El Madrid quedó subcampeón de Liga, ganada por el equipo sevillano del Betis. En las elecciones a la presidencia del club celebradas al acabar la temporada resultó ganador Rafael Sánchez Guerra, una figura de cierta relevancia política. A su puesto de Secretario General de la Presidencia de la República unía el hecho de ser 
hijo del presidente del Gobierno con Alfonso XIII José Sánchez Guerra, con quien fue detenido en Valencia en vísperas de "la final del agua" al promover una intentona golpista contra Miguel Primo de Rivera.

La marcha triunfante del Madrid en los años republicanos continuó durante la temporada 1935-1936. En la liga quedó en segundo lugar, tras el Athlétic de Bilbao. En la Copa alcanzó la final, que disputó en Mestalla ante el F.C. Barcelona. El deporte como espectáculo estaba ya consolidado, lo mismo que los servicios adyacentes que permitían el desarrollo de la industria del ocio. El club madridista organizó dos trenes especiales, cuyos precios oscilaban entre las veinticinco pesetas en tercera clase y las cincuenta de primera. Se salía de la estación de Mediodía el sábado a las once cuarenta y cinco de la noche y se regresaba en la madrugada del lunes. El precio de la entrada eran seis pesetas, el habitual para los partidos de máximo interés. Un partido normal costaba la mitad, tres pesetas, igual que una entrada de teatro y el doble que una de cine de estreno. La expectación por ver la final disparó los precios en el mercado ilegal hasta multiplicarlos casi por diez: "La reventa es un buen negocio en estos momentos. Algunas entradas de general, que valen en taquilla seis pesetas se venden a diez duros [cincuenta pesetas]" $(A B C, 21$ 6-1936: 64).

El partido se disputó el domingo 21 de junio de 1936. El Madrid ganó el partido por 2 goles a 1. La parada que realizó Zamora poco antes de concluir el partido a Josep Escolá se ha convertido en uno de los iconos del periodismo deportivo español. El recibimiento que tuvieron los vencedores a la llegada a Madrid, con decenas de miles de seguidores por la calles, fue apoteósico, como se aprecia en los abundantes reportajes de la prensa (Ver, por ejemplo, Ahora, 23-6-1936: 16-18). Los actos destinados a celebrar el título más valorado del fútbol demuestran la pasión que suscitaba el espectáculo:

Quien se haya propuesto seguir todos los actos realizados durante la semana en honor de los ganadores de la Copa de España, habrá tenido que despedirse de la familia. Todos los días fiestas, funciones teatrales en la mayoría de los coliseos que hacen temporada estival en Madrid; velada de catch, banquetes íntimos, banquetes populares, cocktails y, naturalmente, en Chicote un agasajo postinero..."7.

El fútbol generaba alegrías que hacían olvidar momentáneamente las tensiones políticas que vivían la población. Ciudadanos de todas las clases sociales e ideologías celebraron en la calle el éxito deportivo, demostrando la esencia de un espectáculo de masas. Los ciudadanos pudieron, por un día, dar rienda suelta a su emoción. El Madrid consiguió, desde la llegada de Zamora en el verano de 1930, formar un equipo ganador, que disputó al Athlétic de Bilbao la supremacía del fútbol nacional. Logró dos Copas de España y dos Ligas, por tres Copas y tres Ligas de los vascos. Sólo dos equipos sevillanos, el Betis que ganó una Liga y el Sevilla que venció en la Copa, lograron un trofeo nacional en los años republicanos al margen de madrileños y vizcaínos. En estos días, Zamora anunció su retirada de los campos de juego (Ya, 27-6-1936: 9). El final de su vida deportiva suponía la conclusión de una etapa del fútbol español, la de los años veinte y treinta, que vivió la consolida- 
ción del fútbol como espectáculo de masas. La sublevación militar del 17 de julio de 1936, que desembocó en la Guerra Civil, hizo que coincidiera con un auténtico final de etapa, la del brillante fútbol de la segunda República. El empuje con el que regresó el fútbol tras la guerra demostró hasta qué punto se había integrado este espectáculo en la sociedad española.

\section{Los medios de comunicación de masas informan sobre el fútbol}

El fútbol creció al mismo tiempo que aumentó la capacidad de consumo de amplias capas de la población urbana española a partir de 1920. "Los cambios en la sociedad española condujeron a la constitución de la norma de consumo de masas en los años veinte. Un norma aún incipiente, centrada en las clases medias que se habían enriquecido con los negocios de la guerra mundial y los sectores burocráticos impulsados por la concentración de capital y la presencia de empresas extranjeras" (González Calleja, 2005: 267). Los nuevos hábitos de vida y consumo de la sociedad urbana se difundieron a través de los medios de comunicación de masas.

La prensa, la radio y el cine conocieron un espectacular crecimiento en toda Europa durante las décadas de 1920 y 1930. Su expansión tuvo relación con la ampliación del tiempo de ocio de los ciudadanos. A través de los periódicos y los programas radiofónicos se difundían los elementos básicos de la cultura, entre los que se contaba el disfrute del tiempo libre asistiendo a los partidos de fútbol. El deporte proporcionaba buenas noticias para los lectores y los artículos de la prensa estimulaban el deseo de asistir a los encuentros. La simbiosis entre ambos ámbitos fue perfecta. Hasta los años veinte, la información escrita no tuvo competidor pero, desde esa década, la radio y el cine se unieron a esta tarea y transmitieron los hechos más destacados de la actualidad. Conviene recordar la presencia de la fotografía, que se convirtió en un apoyo fundamental para la difusión de la información en periódicos, revistas y carteles publicitarios. Es frecuente que se identifique esta sociedad con una población alienada: "la cultura de masas sería el producto negativo de la revolución tecnológica en los medios de comunicación" (Giner, 1998: 170). Este tópico olvida los efectos positivos que genera un modelo en el que la población, bien informada, es capaz de tomar decisiones que se ajustan mejor a sus necesidades.

Los periódicos abandonaron el modelo decimonónico, basado en prestar atención sólo a la política y adoptaron un esquema enciclopédico, pues en su interior cabían artículos de economía, cultura, vida social, opinión, política y, por supuesto, deportes, todo ello acompañado por una publicidad creciente que permitía asumir los gastos que acarreaba publicar el diario. La aparición de noticias deportivas comenzó en los diarios de Estados Unidos en la década de 1880. Al cabo de unas décadas, el modelo norteamericano se consolidó en Europa y, por supuesto, en Madrid. Los actos relacionados con el mundo del ocio ganaron espacio en las publicaciones. Abrieron el camino las actividades más apegadas a la tradición cultural, como el teatro, la música clásica y la información taurina. Después ganaron espacio los nuevos espectáculos, como el cine y el fútbol. 
El progreso de la prensa estuvo ligado a las mejoras en educación y cultura. El aumento de las tasas de alfabetización permitió que más personas accedieran a la prensa. En Madrid el porcentaje de personas que sabían leer y escribir pasó del $60 \%$ en 1920 al $80 \%$ en 1930. El periódico buscaba una clientela interclasista, que encontrara en la prensa cualquier información que pudiera necesitar. La sociedad española, sujeta al inmovilismo político de la dictadura del general Miguel Primo de Rivera, experimentó unos profundos cambios en sus hábitos de vida: las ciudades se llenaron de coches, se construyeron grandes plazas de toros, cines y estadios de fútbol, aparecieron nuevos ritmos musicales y, en general, se produjo una modernización de las costumbres. El ocio, y más en particular la actividad deportiva, entró poco a poco en la prensa escrita, primero con la palabra inglesa sport y luego con la denominación española. El 7 de junio de 1911 fue la primera vez que el diario El Imparcial imprimió la palabra Deportes. Los diarios tardaron en dar una ubicación estable a las crónicas dedicadas a los deportes. El éxito conseguido en los Juegos Olímpicos de Amberes de 1920 contribuyó a aumentar su presencia en la prensa escrita.

En 1920 el segundo puesto en fútbol y polo, en Amberes, suscitó los entusiasmos generales, llevó la idea del deporte al periódico diario, al casino pueblerino, al hogar medio, a la masa, y de golpe y porrazo, el sport tomó carta de naturaleza en España y quedó incorporado a las costumbres españolas ${ }^{8}$.

La difusión de los deportes en la prensa afectó a todos los rotativos. El Sol, el diario por excelencia de los intelectuales liberales, concedió una extensión cada vez mayor a sus informaciones sobre el fútbol. Este periódico no publicaba información taurina, ya que se oponía a las corridas de toros. A finales de los años veinte, de las ocho páginas del diario, algunos ejemplares contenían tres dedicadas a los deportes. El mayor número de noticias correspondía al fútbol, aunque era abundante la información sobre pelota vasca, boxeo, hípica o "basket-ball". Desde 1926, todos los días hubo noticias de fútbol en el diario, algo que no alcanzaron las demás disciplinas deportivas (Polo del Barrio, 1993: 184 y apéndice 2, 391). El caso de este diario es extrapolable al resto de la prensa madrileña. El deporte se había convertido en parte indisoluble del ocio en la ciudad y el fútbol era su primer abanderado.

La primera revista especializada en el ocio publicada en Madrid fue Gran Vida, que apareció en junio de 1903 y se subtitulaba Revista ilustrada. Turismo, deportes, fotografia, páginas financieras. Recogía información sobre estos temas, pero el que mayor extensión alcanzaba era el deporte, lo que era un signo de modernidad. Se dirigía a un público de alto nivel adquisitivo e incluso mostraba noticias sobre la Bolsa e inversiones. Sus contenidos confirmaban la visión de que el deporte, a principios del siglo XX, era un entretenimiento sólo accesible a personas adineradas. Este concepto cambió situación en el breve plazo de una generación. Hasta la década de 1920, consideraba al fútbol como un deporte más, pero desde ese momento, las noticias relacionadas con el balompié superaron con creces a las dedicadas a otras disciplinas deportivas. El avance del ocio hizo que surgieran otras revistas especializadas. En 1915 nació Heraldo Deportivo, en 1923 Aire Libre, Excelsior en 1924, en 1926 apareció Noti-Sport, agencia especializada en deportes y en 1928 llegó el sema- 
nario Estampa, que trataba temas relacionados con el fútbol y el cine, mientras que se oponía a la tauromaquia.

Los periódicos actuaron como una propaganda encubierta. Los espectáculos que se reseñaban recibían el elogio del cronista de turno. Se puede pensar que en ocasiones la prensa no mostraba lo que sucedía, sino lo que gustaría que hubiera (Magnien, 2002: 110 y ss.). Los cronistas hablaban de miles de aficionados que contemplaban el deporte rey, entusiasmados con el juego. Se resaltaba la presencia de mujeres en los estadios como un signo más de la integración femenina en la sociedad. Los artículos de algunos periodistas parecían redactados por los propietarios de los clubes. Hasta tal punto llegó la confusión entre información y publicidad, que El Sol advirtió, el 12 de diciembre de 1925, que las noticias que anunciaran partidos de fútbol se considerarían propaganda y, por lo tanto, cobrarían por incluir estas notificaciones. El fútbol era una fuente de buenas noticias para la gente, un motivo de diversión entre los problemas cotidianos. Pero los resultados también importaban. Si la selección o el equipo favorito ganaban, la noticia se recogía con un gran despliegue de medios. En caso de derrota, bastaba una pequeña reseña.

Otra característica de la relación entre la prensa y el fútbol consistió en la identificación de los diarios con un equipo de la ciudad. El Real Madrid fue el equipo preferido por los diarios, gracias a que sus triunfos le proporcionaron un mayor número de seguidores. Dos sucesos del año 1923, separados por tan sólo dos semanas, mostraron esta situación. El traslado del Real Madrid al campo de Ciudad Lineal tuvo un despliegue en la prensa muy superior al que alcanzó la inauguración del Stadium Metropolitano, un recinto más moderno, de mayor aforo y en el que iban a jugar los demás equipos inscritos en el Campeonato Regional. El equipo blanco generaba más volumen de información que los otros clubes madrileños.

A mediados de los años veinte un nuevo medio se sumó a las tareas informativas, la radio. Desde la década anterior se había extendido el gusto por las transmisiones por parte de algunos aficionados a las ondas. La "radiomanía" se convirtió en un tema de conversación habitual entre los madrileños, hasta el punto de que con este término se escribió un cuplé, cantado por la popular Cándida Suárez (Díaz, 1999: 156). Las siglas de la telegrafía sin hilos, TSH, alcanzaron una gran difusión, hasta el punto de que fue el título de una revista presentada por los famosos cómicos Loreto Prado y Enrique Chicote TSH o los pollos de las ondas, que se presentó en el teatro de La Latina el 17 de octubre de 1924. Estas siglas sirvieron de titular a una revista publicada por la emisora Radio Ibérica. Con la radio llegó también la novedad del pago aplazado. Los receptores de galena, con auriculares, costaban dieciocho pesetas, que se podían pagan en tres plazos mensuales de seis pesetas. En 1925, un receptor de radio de seis lámparas dotado de altavoz costaba doscientas ochenta pesetas a pagar en veinticinco meses, con plazos mensuales de poco más de diez pesetas.

La principal emisora radiofónica de los años veinte y treinta fue Unión Radio, vinculada a un poderoso grupo empresarial que incluía entre otras multinacionales a la norteamericana RCA, la británica Marconi y la alemana Telefunken. Su primera emisión tuvo lugar el 17 de junio de 1925 desde sus estudios en la Gran Vía, en el 
mismo edificio donde se ubicaban los almacenes Madrid-París. Esta jornada contó con la presencia de Alfonso XIII y el jefe del gobierno, Primo de Rivera. La compañía estaba dirigida por Ricardo Urgoiti, hijo de Nicolás de Urgoiti, editor de El Sol. La empresa nació con vocación de convertir la radio en un medio de comunicación accesible a toda la población. Para ello era necesario contar con ingresos procedentes de la publicidad. De la programación de las primeras emisoras, que buscaban una audiencia elitista y estaban basadas en la difusión de música o temas científicos, se pasó a una parrilla en la que se trataban asuntos de actualidad. Igual que ocurrió con el fútbol, la radio empezó siendo un entretenimiento para la clase alta, pero pronto se democratizó y se convirtió en un entretenimiento de masas.

El primer partido que se radió fue ofrecido por Unión Radio y tuvo lugar el 8 de mayo de 1927. Se trató de la semifinal de la Copa del Rey disputada en Zaragoza entre el Real Madrid y el Real Unión de Irún. Sin embargo, las retransmisiones deportivas tardaron en ser habituales. Este mismo año se estrenó la película ;Por fin se casa Zamora! cuyo máximo atractivo era su presencia en la cinta, lo que demostraba el fuerte atractivo que ejercía el portero sobre la población.

La principal fuente de información seguían siendo los periódicos. La trascendencia de la noticia en los periódicos dependía de los intereses de los editores. La "final del agua", disputada en febrero de 1929, al poco tiempo del fracasado golpe de Estado de Sánchez Guerra, no fue merecedora de la portada del diario $A B C$, como hubiera sido normal dada la expectación del partido y los miles de madrileños desplazados para asistir al encuentro. En su lugar se prefirió una fotografía de un conflicto minero en Inglaterra. El rotativo seguía la estrategia de mostrar los problemas del extranjero, olvidando el conflicto interno que en esos días supuso la intentona golpista.

La victoria de la selección española sobre los ingleses, el día de san Isidro de 1929 fue ampliamente recogida por todos los diarios. "La prensa de la época no ahorró alabanzas para los jugadores nacionales, encabezados por Zamora. Numerosos testimonios consideran este partido un punto de inflexión en el fútbol español, tanto desde el punto vista deportivo como por su capacidad de atracción hacia los espectadores, que le daba un puesto puntero en la industria cultural" (Samaranch, 1994: 845).

El cine se hizo eco de la información futbolística en noticiarios que se exhibían en las salas. La presencia de estas filmaciones era un buen reclamo para los espectadores y demostraba el interés que suscitaban las competiciones. Así se apreció en el diferente interés que generó, en la temporada 1928-1929 el final de la Copa y la conclusión del primer campeonato de Liga. Mientras que la final disputada en Valencia mereció la proyección en el madrileño cine Avenida de la Revista de la final del campeonato de fútbol, jugado entre el Club Deportivo Español, de Barcelona y el Real Madrid, Fútbol Club, la conclusión de la Liga no tuvo su reflejo en las pantallas.

La relación de la gran pantalla con el fútbol continuó de forma esporádica. El 7 de enero de 1930 se estrenó Fútbol, amor y toros, del director Florián Rey, el primer film sonoro español ${ }^{9}$. De manera significativa se unían los dos grandes y nuevos 
entretenimientos de los que gozaban los madrileños, el cine y el fútbol, a los que se añadía el tradicional espectáculo taurino. La cinta no gozó del favor del público, en parte por los problemas de sincronización entre la imagen y el sonido que había preparado Ricardo Urgoiti, en parte por la escasa calidad de una cinta que incidía en las imágenes tópicas sobre nuestro país.

Los años de la Dictadura experimentaron el incremento de la información dedicada al fútbol, pero no se puede considerar una imposición del gobierno a las empresas editoras. En los años treinta, cuando las libertades en España alcanzaron unas cotas inimaginables poco tiempo antes, las noticias sobre fútbol y otros espectáculos, como el cine, el teatro, los toros o la música continuaron su aumento con respecto al período anterior. El desarrollo de la conciencia política convivió con la voluntad de disfrutar del tiempo de ocio con los entretenimientos que proporcionaba la sociedad industrial. La información futbolística no era una forma de desmovilizar a la población sino la consecuencia del interés que sentían los lectores por los temas lúdicos.

La radio se benefició en los años treinta del interés de la población por el fútbol. Las retransmisiones permitían multiplicar los ingresos gracias a la inclusión de cuñas publicitarias. Los aficionados también se beneficiaron, pues podían seguir la marcha del encuentro en directo. En esta década se convirtió en una costumbre acudir a la taberna a escuchar el partido con otros amigos que carecían de aparato receptor. Los locutores aprovechaban las retransmisiones para comentar aspectos del reglamento que aumentaban los conocimientos de los oyentes. Los boletines informativos ofrecían los resultados de la jornada, permitiendo a los forofos estar al día de la marcha de los partidos.

Los periódicos ofrecían en la edición del martes una amplia información de la jornada futbolística, tanto escrita como fotográfica. Las crónicas correspondían a todos los equipos, no sólo a los madrileños. La información deportiva no era monopolio del fútbol. Se recogían los resultados de los combates de boxeo, pruebas hípicas, competiciones atléticas, pelota o cualquier otra actividad deportiva. El vocabulario deportivo mantuvo la dependencia de los términos ingleses. Un dibujo humorístico de Bagaria, publicado en El Sol el 25 de mayo de 1925, decía: "Que nos quiten las libertades. ¡Qué importa! -¡Claro está! Mientras nos respeten los goals, que entonces sí que protestaríamos como un solo hombre" (Seoane, 1994: 726). Una década después, en 1936, el pronóstico sobre la final de Copa entre el Madrid y el Barcelona comentaba: "Para que se estableciera esa diferencia de dos goals que consideramos para el Madrid, sería menester llegar a una diferencia de 3-1, lo que significa demasiado score para una final" $(A B C, 18-6-1936: 51)$.

El interés por los temas deportivos provocó que en 1932 aparecieran $A s$ y Campeón, dos semanarios deportivos. As, que llegó a tener una tirada de 150.000 ejemplares y era propiedad de Sucesores de Rivadeneyra, casa que publicaba Ahora, uno de los periódicos más representativos de la segunda República, y Campeón, editado por la empresa de $A B C$. Desde principios de siglo y hasta 1936 se contabilizaron decenas de publicaciones especializadas en deporte, muchas de las cuales no tuvieron ninguna repercusión entre los aficionados. Este volumen explica que en 
1934 se creara la Agrupación de la Crítica Deportiva Madrileña. La existencia de una prensa deportiva tan abundante obligó a los periódicos generalistas a aumentar la extensión que dedicaban a la información deportiva. En 1935 apareció el diario $Y a$, publicación vespertina de la Editorial Católica, que publicaba el matutino El Debate. Desde su aparición, $Y a$ dedicó especial atención a los espectáculos en general y al fútbol en particular. Uno de sus colaboradores era Ricardo Zamora. Otros famosos relacionados con el mundo del deporte firmaron sus artículos en distintas publicaciones. Hernández Coronado, ex-jugador del Real Madrid, escribió en Campeón. El presidente del Madrid, Sánchez Guerra, en $A s$.

Los éxitos deportivos del Madrid C.F. durante la segunda República tuvieron un amplio reflejo en la prensa. Sin embargo, las noticias que más interesaban a los aficionados eran las relacionadas con la Copa de España. El primer triunfo liguero del Madrid, logrado en 1932, sólo se reflejó, en los diarios generalistas, en las páginas de huecograbado, a pesar del inmenso gentío que recibió a los ganadores. El 6 de abril fueron recibidos por el alcalde, Pedro Rico, como atestiguaban las imágenes de los diarios (Ahora, 7-4-1932:14). La noticia quedó relegada a los lectores especializados en el tema deportivo.

El segundo título de Liga, logrado en 1933, alcanzó una difusión similar, limitada a las páginas dedicadas al deporte. La colosal goleada por 13 a 0 que España le endosó a Bulgaria el 21 de mayo en Chamartín tuvo su inmediato reflejo en las pantallas. Para regocijo de los forofos, a los dos días se anunciaba en el cine un reportaje del partido. A diferencia de lo que había pasado con el éxito liguero, la disputa de la final de Copa de ese año, que el Madrid perdió contra el Bilbao, mereció la portada del diario $A B C$. El periódico recogió el momento en el que se sorteaba el campo. El trofeo más importante para los aficionados seguía siendo la Copa, una competición en la que los sentimientos son más intensos que en la Liga, donde se premia la regularidad.

El éxito en la Copa de 1934 tuvo una amplia repercusión en los medios de comunicación. La radio había llevado hasta los aficionados los avatares del encuentro. El diario $A B C$ trajo de nuevo a la portada al equipo blanco, que en esta ocasión sí había ganado el título. Al día siguiente, la triunfal bienvenida que dio la ciudad a sus futbolistas mereció la portada del diario conservador por segundo día consecutivo. Las principales imágenes del encuentro se pudieron ver en las pantallas madrileñas. La consecución del título copero tuvo una repercusión muy superior a la de los triunfos en la Liga.

El último gran éxito madridista de la etapa republicana fue la consecución del título de Copa en 1936. Las imágenes de los principales diarios muestran una ciudad volcada con los vencedores. Por un día se olvidaron las diferencias entre unos y otros, disfrutando de la alegría que proporcionaba este divertido espectáculo. El fútbol volvió a mostrar su capacidad para convertirse en un vínculo de sociabilidad democrática, un ámbito donde compartir emociones con personas de distinta ideología y posición social. En unos años en los que los motivos de tensión eran frecuentes entre los madrileños, el ocio de masas servía como amortiguador de los problemas cotidianos. 
El fútbol, un espectáculo en continuo crecimiento, pasó de las páginas deportivas a los ecos de sociedad. La vida de los futbolistas interesaba a los aficionados y empezaron a difundirse noticias sobre sus gustos, sus relaciones familiares y todo cuanto tuviera relación con estos famosos personajes. La revista Estampa, centrada en la vida de las celebridades, entrevistó a la esposa de Ricardo Zamora, Pilar Galdiano, con motivo del anuncio de su retirada de los campos de juego. Para la mujer del cancerbero se trataba de una buena noticia, pues le permitiría pasar más tiempo al lado de su marido, sin los continuos viajes que le obligaba a hacer su profesión (Estampa, 11-7-1936). La radio y los informativos de cine se ocupaban con profusión del fútbol. El desarrollo de los medios de comunicación de masas, entre 1923 y 1936, avanzó de la mano de la expansión del fútbol y el Real Madrid fue uno de los protagonistas de este crecimiento.

\section{Conclusiones}

La ciudad de Madrid desarrolló entre 1923 y 1936 una sociedad de masas en la que los grandes espectáculos, liderados por el fútbol y el cine, alcanzaron una presencia habitual en el devenir diario de sus habitantes. Este hecho con menudo se ha olvidado en los estudios que tratan el período histórico del final del reinado de Alfonso XIII y de la Segunda República, más preocupados por mostrar lo que separaba que lo que unía a los madrileños y, en general, a los españoles. El ocio se democratizó, pasando de ser un lujo al alcance de las clases altas a ser un derecho al que pudo acceder la mayoría de la población. En el plazo de poco más de una década se vivió una revolución silenciosa que sentó las bases de la pasión por el fútbol que, casi noventa años después, sigue llenando de ilusión la vida de las personas y de noticias los diversos soportes de comunicación. Aparecieron nuevos modelos de competición, para ajustarse a las nuevas necesidades del mercado del ocio. La aparición de la Liga respondió a la lógica del crecimiento de la industria cultural, lo mismo que, años después, ocurrió con la creación de la Copa de Europa, más tarde transformada en Champions League. Los campeonatos de selecciones nacionales se ampliaron, pues a la oferta de los Juegos Olímpicos se añadió el Campeonato del Mundo.

El desarrollo de esta industria convivió con los momentos de mayor movilización política que había conocido la sociedad española hasta ese momento. El ocio no actuó, en contra de la opinión de algunos pensadores, como elemento de desmovilización política y dominación ideológica, sino que fue un complemento en la vida de las personas. Era imposible que una persona estuviera movilizada las veinticuatro horas del día. Además de acudir a mítines o participar en debates sobre la marcha del país, los madrileños disfrutaron de la diversión que proporcionaba el fútbol. El Real Madrid logró convertirse en el equipo con el que se identificaron sus conciudadanos. Curiosamente, el momento de mayor auge del club coincidió con la etapa republicana, momento en el que tuvo de dejar de ser "Real" por imperativo legal. El Madrid F.C. se convirtió en uno de los grandes dominadores del fútbol nacional en los años 
republicanos.

Los medios de comunicación dieron buena cuenta de esta evolución, primero a través de la prensa y después con las noticas en la radio y el cine. El desarrollo de ambas disciplinas, información y deporte, corrió paralelo, beneficiándose mutuamente del interés que generaban entre los madrileños los encuentros de fútbol y la oportunidad que les servían los medios de comunicación de recibir estas noticias. Diarios de información general con una cantidad de noticias dedicadas al deporte cada vez mayor, revistas especializadas en fútbol, agencias de noticias de deportes, programas de radio que comentaban la actualidad o retransmitían los partidos, toda una industria de la información volcada con el deporte rey.

\section{Bibliografía}

BAHAMONDE MAGRO, Á. (2002). El Real Madrid en la historia de España. Madrid: Taurus.

DÍAZ, L. (1999). La España alegre. Ocio y diversión en el siglo XX. Madrid: EspasaCalpe. Colección Espasa hoy.

ELIAS, N.; DUNNING, E. (1992). Ocio y deporte en el proceso de la civilización. México: Fondo de Cultura Económica.

GARCÍA, J. J. (1993). Atlético de Madrid. Historia del Club. 90 aniversario 1903-1993. Madrid: De Horna.

GINER, S.; LAMO DE ESPINOSA, E.; TORRES, C. (eds.) (1998). Diccionario de Sociología. Madrid: Alianza.

GONZÁleZ CALleJA, E. (2005). La España de Primo de Rivera. La modernización autoritaria. 1923-1930. Madrid: Alianza.

MAGNIEN, B.; ROBIN, C. N.; TRENT, E. (2002). "La culture au quotidien". En SERRANO, C. ; SALAÜN, S. (2002). Temps de crise et "années folles". Les années 20 en Espagne. Paris : Presses de l'Université de Paris-Sorbonne, p. 109-154.

MOYA, A. (1990). Metro de Madrid 1919-1989. Setenta años de historia. Madrid: Metro.

POLO DEL BARRIO, J. (1993). El fútbol en Madrid. De actividad lúdica a espectáculo de masas (1898-1945). Tesis doctoral dirigida por Ángel Bahamonde Magro. Madrid, Universidad Complutense.

SAINZ DE ROBLES, F. C. (et al.) (1952). Libro de Oro del Real Madrid C. De F., 19021952. Madrid: Ares.

SALAZAR Y ACHA, B. de (dir.) (2003). Cien años del Atlético de Madrid. Madrid: Diario AS.

SAMARANCH, J. A. (1994). "Los deportes". En MENÉNDEZ PIDAL, Ramón (dir.) (1994). Historia de España. Vol. XXXIX. La Edad de Plata de la Cultura Española (1898-1936). Letras. Ciencia. Arte. Sociedad y culturas. Madrid: Espasa-Calpe. p. 831-848.

SCHER, A. (1988). Fútbol: pasión de multitudes y de elites. Un estudio de la Asociación de Fútbol Argentino (1934-1986). Buenos Aires: Centro de Investigaciones Sociales sobre el Estado y la Administración. 
SEOANE, M. C. (1994). "La prensa". En MENÉNDEZ PIDAL, Ramón (dir.) (1994). Historia de España. Vol. XXXIX. La Edad de Plata de la Cultura Española (18981936). Letras. Ciencia. Arte. Sociedad y culturas. Madrid: Espasa-Calpe, p. 701-730. VARIOS AUTORES (2002). Historia del Real Madrid, 1902-2002. La entidad, los socios, el madridismo. Madrid: Everest.

\section{Prensa y Revistas}

$A B C$ (Madrid), 1923-1936.

Ahora, 1930-1936.

As, 1935-1936

Boletín Informativo del Real Madrid (BIRM), 1950.

El Sol, 1923-1936.

España Sportiva, 1917-1926.

Estampa, 1928-1936.

Gran Vida, 1923-1936.

Heraldo de Madrid, 1923-1936.

Ya, 1935-1936.

\section{Notas}

$1 \quad A B C, 27-2-1923$.

$2 A B C, 19-6-1923$.

3 España Sportiva, 26-8-1926.

4 Santiago Bernabéu fue presidente del club desde 1943 hasta 1976. El 2 de enero de 1955 el estadio de Chamartín cambió su nombre para denominarse con el nombre de su presidente.

5 Gran Vida, mayo-1929.

6 Heraldo de Madrid, 26-3-193.

7 As, 29-6-1936.

8 El Sol, 14-4-1927.

9 Esta película se estrenó unos días antes que El Misterio de la Puerta del Sol, dirigida por Francisco Elías, que fue la primera película española grabada con un sistema sonoro, pero su primera proyección se produjo el 11 de enero de 1930, en Burgos. 


\section{El autor}

José María Báez y Pérez de Tudela es doctor en Humanidades, Geografía, Historia y Arte por la Universidad Carlos III de Madrid y ejerce como profesor de Enseñanza Media. Sus publicaciones incluyen libros de texto y estudios sobre la política y el deporte en la Historia Contemporánea de España. Sobre estos temas ha publicado la obra Fútbol, cine y democracia. Ocio de masas en Madrid, 1923-1936. 